\title{
REGIMES JURÍDICOS FUNDIÁRIOS NO BRASIL E FUNÇÃO SOCIOAMBIENTAL \\ DA POSSE AGRÁRIA: A REGULARIZAÇÃO FUNDIÁRIA DE POPULAÇÕES
}

RIBEIRINHAS DA VÁRZEA AMAZÔNICA

Karla Rosane Aguiar Oliveiral

\section{RESUMO}

Durante os diversos regimes jurídicos fundiários da história brasileira, as populações ribeirinhas definiram formas de territorialização específicos e vínculos ancestrais nas calhas dos rios amazônicos, porém historicamente sempre viveram em condição de invisibilidade sócio-política. Em virtude das condições de colonização e apropriação da terra no Brasil, valeram-se do instituto da posse como a única opção de acesso à terra. Com a evolução da legislação e das lutas destas populações, havia a necessidade de promover a regularização fundiária que abarcasse o modo de vida caboclo. Assim, este artigo tem como objetivo contribuir com o debate sobre a questão agrária no Brasil, a partir de revisão de literatura e análise do quadro jurídico envolvido. Para isso, enfoca a Concessão de Direito Real de Uso como um dos instrumentos que proporciona ao Estado a garantia da função social dos bens públicos e a segurança jurídica da posse agrária de populações de várzea da Amazônia.

\section{Artigos de Revisão}

Palavras-chave: Posse agrária; Regularização fundiária; Concessão de direito real de uso.

Land tenure regimes in Brazil and the social and environmental purpose of rural land possession: land tenure regularization of riverside communities in the Amazon floodplain

\section{ABSTRACT}

Throughout various legal regimes for land tenure adopted in Brazilian history, riverside communities have established specific forms of territorialization and ancestral ties in the margins of Amazonian rivers but have historically lived in sociopolitical invisibility. Due to colonization conditions and land appropriation practices found in Brazil, those communities have made use of the institute of possession as the only option for access to land. As legislation evolved and the struggles of these populations continued, the need arose to promote a form of land tenure regularization that encompassed the caboclo way of life. Thus, this paper aims to contribute to the debate on the agrarian issue in Brazil based upon a literature review on the matter and an analysis of the legal framework involved. To this end, it focuses on the Concessão de Direito Real de Uso ("Concession of Real Right of Use") as one of the instruments that allows the State to ensure the social function of public properties and guarantee legal certainty for rural land possession by Amazon floodplain populations.

Keywords: Rural land possession; Land tenure regularization; Concession of real right of use Centro Universitário de Araraquara - UNIAR A

-mail: karla oliveiradf@gmail.com 


\section{INTRODUÇÃO}

Durante os regimes jurídicos de propriedade da terra no Brasil, era um fato que a propriedade era concedida/vendida à parcela ínfima da população ere inha possiblidade decomprae venda eaces caminhos da burocracia. A maior parte da população não tinha possibilidade de adquirir terras, o que levou muitos não só ao estado de exclusão, mas também ao reconhecimento de que a terra só poderia ser adquirida por meio da posse informal e não documentada

$\mathrm{Na}$ Amazônia, esta também foi uma realidade. Porém, inicialmente adentrava-se na floresta somente com o fim último de explotação dos recursos. O interesse não era a terra, e sim o aproveitamento econômico dos recursos florestais A colonização da região se deu, portanto, nas calhas dos rios, de onde se organizava toda u de principal de coleta do látex durante o período da borracha.

Assim é que se forma a identidade do ribeirinho da Amazônia: com conformações adaptadas ao ambiente seco/alagado durante períodos do ano, e se contentando em somente se "colocar" na região, e não no intuito de colonizá-la.

Com a evolução deste processo, os ribeirinhos que historicamente possuem relações com a várzea se veem desassistidos dos processos de regularização de suas posses e ameaçados de desterritorialização por não possuírem a documentação da terra. A Posse Agrária, como instituto similarà Propriedade também pode sevalerd à garantia do uso sustentável da terra.

Este artigo tem por objetivo contribuir com a discussão sobre a questão da Função Socioambiental da Posse Agrária no caso das populações ribeirinhas da Amazônia. Para tanto, dá inicialmente um panoram da construção do instituto da posse agrária no Brasil e na Amazônia ao descrever os diversos regimes jurídicos fundiários desde o período colonial. Após, debate como a doutrina e legislação jurídicas tratam a Posse Agrária e sua função socioambiental. Por fim, eva esta discussão ao caso das populações ribeirinhas daAmazônia, buscando focar as suas territorialidades e modos de vida específicos, e como o Estado brasileiro, nos anos recentes, vêm construindo instrumentos que promovam a regularização fundiária destas.

A estratégia metodológica para este estudo é revisão de literatura sobre a história agrária brasileira enfocando em especial a região amazônica, sobre o conceito de posse agrária e sua função socioambiental e sobre a população ribeirinha da Amazônia e seu modo particular de vida. Por fim, analisou-se a Concessão de Direito Real de Uso, utilizando a metodologia de análise juridica da legislação e doutrinas existentes. Espera-se, com isto, que se demonstre a importância da regularização fundiária de posses agrárias na Amazônia ribeirinha, e como o Estado pode garantir a segurança jurídica a esta população tradicional e a função socioambiental de terras públicas da União.

\section{Histórico dos regimes}

\section{jurídicos fundiários no Brasil}

\section{e na região amazônica}

A origem do direito fundiário brasileiro é oriunda da estrutura fundiária portuguesa. A Lei de Sesmarias de 1375 , que teve como objetivo disciplinar o uso e a ocupação do solo no território português, colocava que "todo possuidor de imóvel agricultável estava obrigado a dar a sua propriedade ou herdade um fim social" (CARVALHO, 1999, p. 16), ou seja, deveriam produzir alimentos para a população. Caso contrário, as terras seriam confiscadas pela Coroa e dadas a quem quisesse produzir.

A lógica do sistema sesmarial somente se adaptou a nova condição da colônia. E Guimarães (2011) complementa que nestes processos adaptativo, quando mais se necessita de coação econômica, mais instrumentos extra-econômicos são mobilizados para esta coação. Exemplo disto é a estrutura so versus vassalos, havia os que detinham o domínio das terras (os "homens de calidad") e a enorme parcela da população em condição de miserabilidade e sem acesso à terra

Porém, este sistema garantiu o caráter exportador à empresa colonial implantada aqui (GUIMARÃES, 2011). O período aurífero no Brasil (séculos XVII e XVIII) acentuou ainda mais a desigualdade social da época, porém em nada alterou no domínio do latifúndio. $\mathrm{Cr}$ declínio da atividade agrícola e terras abandonadas (FERES, 1990).

O Direito Fundiário define como o período de 1534 1822 como o Regime das Sesmarias (CARVALHO, 1999), em que as terras brasileiras eram consideradas possessão da Coroa Lusitana, e as sesmarias eram concessões de terras da concess des derros sob instituto da função social da propriedade. Este é o primeiro regime jurídico de terras no Brasil. Note-se aqui que as terras eram originariamente públicas; somente se tornavam particulares após o cumprimento de alguns requisitos, dentre estes, a confirmação real da concessão da sesmaria. Caso não possuísse a confirmação, a sesmaria deveria ser "devolvida" ao patrimônio público (TRECCANI, 2006).

$\mathrm{Na}$ região amazônica, durante os anos de consolidação da presença ibérica, era o Rei que distribuía diretamente o controle das terras para pessoas de sua confiança. Devido às dificuldades de se chegar às instâncias reais, das 2.158 cartas de sesmarias concedidas no Grão Pará ${ }^{1}$, somente 560 foram realmente efetivadas (SILVEIRA, 1994 apud TRECCANI, 2006). Isto dificulta qualquer identificação de cadeia dominial na Amazônia e conexão com eventuais ocupantes atuais(TRECCANI, 2006).

Em 1822, a Coroa extingue o Regime Sesmaria pela Resolução Imperial de 17 de julho (MATTOS NETO, 2006; TRECCANI, 2006), porém deixando um vazio legal. O Regime das Posses (CARVALHO, 1999), de 1822 a 1850 provoca um enorme estado de insegurança jurídica e aumento da violência no campo. Este foi o segundo regime jurídico fundiário no Brasil A posse foi o instituto empregado pelo camponês região que, diferentemente do que ocorria como o restante da Colônia governada diretamente pelo Rei de Portugal, visto que pelo Tratado de Tordesilhas a maior parte do Grăo Pará pertencia ao domínio espanho. pobre para se estabelecer e produzir nos "fundos dos latifúndios" durante o Regime Sesmarial. Assim, já era de conhecimento de que pequenos agricultores e escravos fugidos aproveitavam tanto pequenos espaços ou desconhecimento do sesmeiro) para moradia e trabalho. Mas, com a queda do Regime Sesmarial, não havia mais nenhuma outra forma de obtenção jurídica de terras. Grandes proprietários, então, começaram a se valer do instituto da posse, pois o mais importante era garantir a ocupação independente do uso e sem se importar com pequenos posseiros (que eram muitas vezes violentamente expulsos). Durante este período, a terra era considerada somente como reserva de valor (FERES, 1990).

A maior parte da população no Brasil esteve apartada do processo de distribuicão de terras, sem acesso aos para garantir o jus possidendi, ou o domínio do possuidor-proprietário. Assim, o jus possessionis, ou a posse do possuidor não proprietário, configura a forma mais comum de obtenção de terras para a maior parte da população (MARQUESI, 2012). O camponês contentava-se com a mera posse física do local.

$\mathrm{O}$ terceiro regime fundiário brasileiro veio somente 30 anos depois da extinção do regime sesmarial, com a promulgação da Lei de Terras em 1850, período que Mattos Neto (2006) chama de Regime das Leis de Terras (Lei no 601/1850). Porém, a literatura enfatiza que, pelo fato desta estabelecer que a unica forma de aquisição de terras públicas se dá pela venda (inserindo de forma abrupta o sistema sesmarial à lei de mercado), esta norma promoveu ainda mais a exclusão da maior parte da população e aumento da desigualdade social. OCódigo Civil de 1916, também com um caráter bastante privatizante, aprofundou ainda mais as relações jurídicas entre privados em relação à terra.

Muitas idas e vindas de uma legislação que já era frágil, e ficou mais manca com a descentralização da competência de legislar aos Estados ocorrida após a proclamação da República em 1891, fez com que se instaurasse uma situação de caos de domínio e posse 
Apesar de todas estas normas legais em toda a Amazônia durante muito tempo continuou a perdurar uma prática comum: quem quisesse estabelecer uma cultura regular desmatava una àrea, plantava uma roça, construla no inovel tha cabana de palha e se fixava no lugar. Diante da total ausencia do Estado, as autoriades, hormalmente, sequer chegavam caminho para garantir a posse

As diversas lutas no campo existente desde o seculo XIX demonstram que o problema fundiário em torno do domínio e posse efetiva da terra aprofunda-se, sempre com muita violência. Transpondo para meados do século XX, o advento do Estatuto da Terra (Lei n 4.051 de 30 de novembro de 1964), em um contexto de ditadura militar promove um arrefecimento do discurso sobre reforma agrária, mas não elimina as injustiças do campo. Este é o quarto regime fundiário do país.

A visão de reforma agrária branda dos militare tinha muito mais a ver com a noção de modernização da agricultura brasileira que a promoção da justiça social. Poucas mudanças nas relações trabalhistas se estabeleceram, continuando a massa de trabalhadores temporários ou pequenos proprietários descapitalizados (FERES, 1990)

Feres (1990) problematiza o aumento da concentração de terras e de renda no meio rura durante o período ditatorial ${ }^{2}$, e que a forma de acesso à propriedade continuava ser a posse. É somente a partir do Estatuto da Terra que a função social da propriedade passa a ser disciplinada como materia legislativa (artigo $2^{\circ}$ ), e elenca que os requisitos da propriedade devem ser o fator econômico (aproveitamento racion equado), o fator anto e adequado), o fator aniental (proteção ambiental), e social (justiça social e bem-estar dos proprietário e trabalhadores). Mas, apesar de ter sido uma lei aparentemente progressista, promulgado para realizar a reforma agrária e ser o ponto final de uma luta politica, o Estatuto da Terra abandonou rapidamente essa perspectiva (FERES, 1990).

2 Segundo o autor, o Censo Agropecuario de 1960, os estabelecimentos com mais de 500 ha concentravam $55 \%$ da área agrícola tota.

Na Amazônia, o lema “Integrar para não entregar" dos militares mudou radicalmente a sociedade amazônica, a partir da abertura do modal viário terrestre e as áreas no entorno destas rodovias federais, sendo estas terras federalizadas e parte destinadas a não se davam mais somente por meio fluvial, mas pela penosa mobilidade das rodovias, com reflexos no crescimento dos centros urbanos (BECKER, 2005).

Mesmo com o princípio da função social da propriedade explícito na legislação vigente, ainda sim os movimentos sociais camponeses aumentaram suas queixas em relação à pauperização e aumento da violência no campo (especialmente na região Nordeste e Norte) nos anos 1970, auge da ditadura militar. Com o fim da ditadura e início do período democrático, a Reforma Agrária surge no contexto de contestação dos novos movimentos sociais (FERES, 1990).

Becker (2005) sustenta que os grandes conflitos de terras e de territórios das décadas de 1960 a 1980 constituíram em um aprendizado político para a sociedade amazônica. Tais conflitos redundaram, na década de 1990, em propostas e projetos alternativos, com base na organização é que trouxe mudanças no apossamento do território amazônico por grupos étnicos.

AConstituição Federal de 1988 abarcou a Função Social da Propriedade, colocando-a como princípio fundamental, em seu Art. $5^{\circ}$. Promove, portanto, o quinto regime fundiario no Brasil. AReforma Agrária no âmbito do Estado Democrático de Direito, deve ser dirigida a partir das diretrizes da política agrícola, de acordo com o artigo 186 da Carta Magna. Porém, o modelo implantado no restante do país não conseguia se adequar à realidade do amazônida. Não é possível definir tamanhos de lotes específicos para populações que se territorializam por medidas referentes a recursos florestais; ou mesmo pela mescla de áreas de uso individual/familiar e áreas de uso comum.

Após a década de 1970, em que intensa luta pela terra foi deflagrada e as críticas ao desmatamento da floresta tornaram-se mais enérgicas, a partir dos algumas propostas de regularização fundiária adaptadas à Amazônia. Dentre elas estão os Projetos de Assentamento Extrativistas (PAEs) e as Reservas Extrativistas (RESEX), amparados pelo Programa Nacional de Reforma Agrária e pelo Sistem Nacional de Unidades de Conservação (SNUC, Lei $\mathrm{n}^{\circ}$ 9.985/2000).

Allegretti (1994) faz um panorama da formulação do conceito de Reserva Extrativista. Quanto aos aspectos jurídicos institucionais da proposta, havia a preocupação principal de regularização fundiária das áreas de posse tradicionais. $\mathrm{O}$ importante era reconhecer e assegurar aos extrativistas direitos que eles já possuíam historicamente; era a compatibilização do uso tradicional, dos direitos de posse e da garantia de futuras explorações. Assim, à semelhança das áreas indígenas, o importante era delimitar um território especialmente protegido que garantisse os limites das antigas áreas de exploração.

A partir dos anos 2000 , tendo em vista uma série de dificuldades para a regularização fundiária das Unidades de Conservação, outras políticas públicas tornaram efetiva a regularização fundiária individual e coletiva a partir de outros instrumentos jurídicos, tendo como exemplo, a Concessão de Direito Rea de Uso (CDRU), que será detalhada mais a frente.

\section{A Posse Agrária e sua \\ função socioambiental}

A partir da história da construção social da propriedade no Brasil, o instituto da posse agrária pode ser considerada em igualdade à propriedade. Segundo Marquesi (2012), a posse agrária também cumpre uma função socioambiental. Ela é vista como uma questão social, e desta deve-se ter o prisma de seu papel econômico, social e ambiental.

Há muita controvérsia na doutrina se o instituto da posse pode ser tratado como direito real ou direito pessoal. A diferença das duas teorias reside no sujeito passivo que incide tal direito: o exercício da posse pelo possuidor afeta um sujeito passivo, que pode ser indeterminado ou um sujeito específico (GOMES,
1983; MARQUESI, 2012). Ou seja, um possuidor, ao exercer a posse, pode atingir um sujeito específico indeterminado, que pode ser a coletividade.

O objeto da posse é uma coisa corpórea. Gomes (1983), mais partidário da doutrina do direito real, argumenta que

"Na posse, a sujeição da coisa à pessoa direta e imediata. Não há um sujeito passivo determinado. O direito do possuidor se exerce erga omnes3. Todos são obrigados a respeitalo. Só os direitos reais tên (GOMES, 1983, p. 27-28)

Porém, Marquesi (2012) conceitua posse mobiliária, ressaltando que nesta está imbuído a função socioambiental.

“(...) [é o exercício do] poder de fato, juridicanento prote social e ambiental, que confere ao titula direitos pessoais ou reais de uso e gozo sobre uma coisa. Como simples fato, a posse ser tutelados pelo direito" (p. 62, grifo meu).

Os artigos 1.196 a 1.224 do Código Civil (Lei $\mathrm{n}^{\mathrm{o}} 10.406 / 2002$ ) são os que regem atualmente as caracterização dos tipos de posse, a direta e a indireta. São importantes para o direito agrário visto que o possuidor direto é o que possui contato físico com a coisa e o segundo é o que dela recebe os benefícios, e nesta relação existem consequências práticas, tal qual o interdito do possuidor direto sobre o indireto $\mathrm{e}$ vice-versa (MARQUESI, 2012)

Outra categorização de posse importante para a não repugna ao Direito, é posse justa (Art. 1.200, $\mathrm{CC})$. Se se utiliza de violência, clandestinidade e/ ou precariedade, é posse injusta. A posse justa deve ser pública e contínua, para que o interessado na sua 3 Efeito erga omnes é aquele que atinge a todos; o sujeito passivo é a
coletividade. (p. ex. o proprietário do domínio), ou um sujeito implica apenas poderes que podem ou ñ̃o relações de posse. Neles, podemos destacar a primeira 
extinção possa opor-se a ela, e o possuidor legitime-a pelo exercício manso e pacífico (GOMES, 1983).

A posse injusta pode ser violenta (adquirida pela força), clandestina (adquirida às ocultas, mediante artifícios para iludir ou agindo às escondidas) ou precária (adquirida por abuso de confiança, a partir da retenção indevida de coisa a ser restituída). $\mathrm{Na}$ classificação subjetiva da doutrina, a posse de máfé possui os mesmos requisitos da posse injusta. E a posse de boa-fé caracteriza-se pelo estado de ignorância do vício da aquisicão (GOMES, 1983).

Uma última classificaça dada por Marc

(2012) não está disposta no Código Civil, porém ainda mantém efeitos procedimentais nas ações possessórias agrárias. Trata-se de Posse nova e Posse velha. A posse nova data de menos de ano e dia, e é amparada por liminar em caso de reintegração de posse do titular. A posse velha, maior que ano e dia, trata-se de consolidação no imóvel, amparando o possuidor.

Sendo a posse comparável em alguns direitos à propriedade, aquela também se vale de uma função social. Para tanto, é impensável que o possuidor, assim como o titular do domínio, empregue o imóvel para fins estritamente individuais, sendo necessário fazê-lo útil à sociedade e visando o bem estar de todos.

As exigências para o atendimento da função social da propriedade devem observar quatro requisitos dispostos na Constituição Federal de 1988:

Art. 186. A função social é cumprida quando a propriedade rural atende, simulaneamente, segundo critérios e graus de exigência estabelecidos em lei, aos seguintes requisitos: I - aproveitamento racional e adequado; II - utilização adequada dos recursos naturais disponíveis e preservação do meio ambiente; III - observância das disposições que regulam as relações de trabalho,

IV - exploraçãa que favoreça o bem-estar do proprietários e trabalhadores

O Código Civil brasileiro de 2002, seguindo a diretriz da Constituição Federal de 1988, dispõe em seu Art. $1.228 \& 1^{\circ}$ que o direito de propriedade deve ser condicionado às finalidades econômica e social em atenção à proteção ambiental. MARQUESI (2012) lembra que a lei civil torna clara a noção de submissão do direito de propriedade ao princípio da função social elencado na Constituição Federal.

"De fato, o adjetivo social está a demonstrar que a função deve corresponder a um interesse coletivo e não se resume aos interesses do proprietário. Cuida-se de harmonizar os interesses particulares com os interesses coletivos e e essa harmonização que legitima a proteção do domínio" (PEREIRA, 2000 citada por MARQUESI, 2012, p. 106)

A função social da propriedade é disciplinada pelo Estatuto da Terra e pela Lei no 8.629 de 1993. Carvalho (1999) vê que esta "é a bandeira sob a qual se firmará o direito agrário brasileiro, e sem a sua constante busca, não teria qualquer sentido" (p. 77). Assim, a posse agraria igualmente deve contemplar a priorizaça do uso socioambiental, em beneficio da coletividade, garantindo a função social dos bens públicos

Uma das formas de regularização da situação do posseiro em terras públicas é a Legitimação de posse, disciplinada no artigo 29 da Lei $n^{\circ} 6.383$ de 1976. Esta diz que os ocupantes de terras públicas que fizeram as terras produtivas com seu trabalho e de sua família pelo prazo mínimo de um ano e que não sejam proprietários de outro imóvel rural, terão direito à legitimação de suas posses em área de até 100 hectares. Há também a regularização de ocupação de imóveis de domínio da União (Decreto-lei n 9.760/46), mediante inscrição e cadastramento dos (D) antes, sendo porém um instituto bastante precário (DI PIETRO, 2014)

Porém, a posse de ribeirinhos na Amazônia deve tanto atender aos requisitos da função social da propriedade delimitados pela CF/88 quanto beneficiar socialmente estas populações diferenciadas culturalmente. As reivindicações dos movimentos socioambientalistas incorporaram a noção de etnicidade (identidade cultural) em suas pautas.

Treccani (2006) enfatiza que a documentação fundiária expedida para populações tradicionais ainda requer que se incorpore a dimensão da proteção do é só a função social da propriedade é importante para estas populações, mas o respeito às relações de ancestralidade com o ambiente, e territorialidades específicas destas.

\section{Os Ribeirinhos na região amazônica: posse e construção de novos modelos de regularização fundiária}

A formação da população que tradicionalmente habita a região amazônica deu-se desde o período colonial, mesclando o patrimônio indígena já existente ao pequeno camponês que se adaptou à floresta tropical. Em geral, o ambiente de colonização foram as margens dos grandes rios e igarapés adjacentes, sempre com o intuito da atividade extrativa dos recursos naturais. Esta foi a origem do "camponês tradicional" ou "extrativista" da Amazônia

Darcy Ribeiro (1995) destaca em seu livro "O Povo Brasileiro", o Brasil Caboclo 4 , e afirma que a incorporação da floresta tropical da bacia amazônica ao Brasil se deu por patrimônio colonial português, pela formação cultural fundada nas matrizes básicas indígenas e pela emigração de cerca de meio milhão de nordestinos para a exploração dos seringais nativos. A ocupação da região se deu devido à economia exportadora de produtos florestais, primeiramente coleta das drogas do sertão, e após, dos dois fluxos migratórios decorrentes da exploração da seringueira no século XIX e início do XX

A população regional à época dos fluxos migratórios, situada em geral às margens dos rios Amazonas e Solimões, se dispersa por toda a bacia em busca do recurso. As cidades se moldam para abrigar essa nova estrutura produtiva voltada para exportação. Ribeiro (1995), resumindo com muita precisão, diz:

4 Darcy Ribeiro procura em seu livro identificar a identidade étnica dos brasileiros, que se constituulu inicialmente pela reprodução das matrizes basictas, como subprodulo de un "enpreendimento exógeno (1) "protobrasileira" (p. 271), produzindo então suas variantes, o que $\mathrm{m}$ a frente Darcy chama de "Brasis": a cultura crioula, a cultura caipira, a cultura sertaneja, a cultura gaúcha e a cultura cabocla, esta últim predominante na região amazônica.
"Nessa economia, a terra em si não tem qualquer valor e a mata exuberante que a cobre so representa obstáculo para alcançar aquelas raras especies realmente úteis. Não se cogita, por isto, de assegurar a posse legal das terras, como é o caso das regiões de econnia arícola e pastoril. O que importa leva aos seringais e a conscricãa de forç . grifo meu).

O que segurava a economia da borracha amazônica ram o monopólio da produção e os preços praticados. Quando o preço abaixou em virtude da I Guerra Mundial no início do século XX, inviabilizou-se a produção da borracha amazônica (muito ultrapassada tecnologicamente), o que levou à falência diversos patrões e o abandono de muitos seringais.

Os poucos seringais existentes sobreviveram devido a políticas protecionistas e procedimentos bancários. Mas, não alterou em muito a situação do nordestino acaboclado e do nordestino recém-chegado. Estes sofreram e ainda sofrem com um estado de miserabilidade, falta de perspectivas e contato com as doenças tropicais. Por conta do extrativista, sem vínculo com a terra, as cidades amazônicas sentiram o inchaço em suas periferias, com uma população subempregada e de condições de vida precárias.

As sociedades rurais na Amazônia contemporânea podem ser divididas grosseiramente em sociedades indígenas; camponeses "tradicionais" ou históricos (caboclos), oriundos da incorporação colonial da região amazônica; e os neocamponeses, que desde a década de 1970 foram incorporados mediante políticas governamentais (ADAMS et al, 2006).

Apesar das diferenças culturais, estas sociedades possuem em comum uma relativa invisibilidade sóciopolítica (ADAMS et al, 2006). Indígenas ainda buscam formas de se proteger da dinâmica de ocupação da Amazônia, apesar das expulsões de seus territórios, das doenças do homem branco e mais recentemente do conflito com o surto de extrativismo mineral na região e da implementação de grandes obras de infraestrutura Seringueiros (caboclos) também tentam 
propor alternativas de se utilizar a floresta, apontando "como fazer a Amazônia habitável e rendosa" (RIBEIRO, 1995, p. 337), porém representam o "fracasso" dos esforços de integração da Amazônia. E os neocamponeses, por sua vez, que apesar de terem migrado como parte das políticas governamentais de ocupação da Amazônia, são excluídos do projeto desenvolvimentista implementado na região (ADAMS et al, 2006).

A partir de meados da década de 1980, lançou-se a proposta de delimitação dos territórios das populações extrativistas, que levasse em consideração o modelo de distribuição tradicional das comunidades. Os Projetos de Assentamento Extrativistas (PAE) e as Reservas Extrativistas (Resex) foram os modelos propostos pelos movimentos sociais, representado principalmente pelo atual Conselho Nacional das Populações Extrativistas (CNS).

Allegretti (1994) lembra que a forma tradicional de uso dos recursos extrativos na Amazônia esteve centrada no formato de colocação: unidade produtiva familiar formada pelas estradas de seringa ${ }^{5}$ (no caso dos seringueiros) e pelas áreas de caça, pesca, agricultura de subsistência e coleta de frutos. Os tipos de propriedades existentes na várzea são a pequena que se dedica a duas ou mais atividades, e a média grande, que se dedica basicamente à pecuária bovina e bubalina (MCGRATH \& GAMA, 2005).

Em ambientes de várzea deve-se incluir também no formato da territorialidade tradicional a posse e exploração de lagos por comunidades ribeirinhas. McGrath \& Gama (2005) fala que o reconhecimento de um território comunitário nas comunidades ribeirinhas tinha ligação à ideia de propriedade privada da várzea: limites frontal e laterais da propriedade são bem definidos tendo como referência os rios 5 A estrutura fisica de um seringal tíico se dava por alguns elementos. todos constitútidos em modelos que condicionavanu unicamente à exploração do látex. Havia o Barracãã, que concentrava o armazém que fornecia produtos e estocava a borracha coletada. Em geral, era o local
onde morava o gerente. As Colocacoōes eram o local onde os seringueiros onde morava o gerchte. As Colocaçocs cram o local onde os seringueilos látex em borracha (defumacão). Por fim, cada seringueiro possuí sun Estrada de Seringa, uma estrada aberta por um mateiro contratado pelo patrão, que seu início e fim se davam na Colocação, e que ligavam toda heveas em um perímetro que um sering Cognuia explorar rode determinado tempo (SLVA \& SILVA, 2006). principais; os lagos, em geral, situam-se nos fundos dos lotes das famílias, e portanto, eram de domínio daquela comunidade. Ou em outra situação, não há posse do lago, porém há o uso comum do mesmo.

Cruz (2007) caracteriza a forma de territorialização

do que denomina como "camponeses-ribeirinhos".

Cita que nestas populações a unidade familiar e a comunidade se territorializam, a partir do ambiente da várzea construída pelos ciclos naturais dos rios. Há três tipos de territorialidades existentes: I) as agropastoris, onde são instaladas as terras de cultivo, o roçado, o sítio e a morada, tendo áreas individuais/familiares e áreas de uso comum; II) as aquáticas, onde são realizadas as atividades de pesca para autoconsumo e comercial, em que os lagos são, em geral, da comunidade, e os rios de uso comum, inclusive por barcos pesqueiros; $\mathrm{e}$ III) as florestais, que lida basicamente com a retirada de madeira/lenha e produtos extrativistas.

Neste ponto, cabe a observação de que na legislação brasileira, as áreas de várzea são consideradas como bens públicos, de livre navegação e acesso aos recursos pesqueiros, de acordo com o artigo $20 \mathrm{da} C F / 88$. A legislação hoje somente admite às comunidades a definição de regras para a exploração dos lagos (MCGRATH \& GAMA, 2005), tais como os Planos de Uso de Unidades de Conservação.

No estudo de McGrath \& Gama (2005) encontrase uma afirmação que pode tranquilamente ser generalizada para o contexto amazônico: um percentual enorme dos ribeirinhos $(70 \%$ no caso deste estudo) não possui nenhum tipo de documento comprovando o domínio da terra. A maior parte dos ribeirinhos (58\% nas comunidades estudadas pelos autores) adquiriu a terra por meio de herança.

A Concessão de Direito Real de Uso é hoje o instrumento mais utilizado para a regularização fundiária em áreas de várzea. Ela é instituída pelo Decreto-Lei no 271/1967, com o seguinte texto: "errenos públicos ou particulares remuno de "Au gratuita por tempo certo ou indeterminado, como direito real resolúvel, para fins específicos de regularizacão fundiária de interesse social, urbanizacão, industrialização, edificação, cultivo da terra, aproveitamento sustentável das várzeas, preservação da comunidades tradicionais e seus meios interesse social em áreas urbanas"(grifo meu)

Sendo as áreas de várzea terras públicas, sem possibilidade de transferência do domínio para o ente privado, o legislador valeu-se de um instrumento que pode possibilitar ao menos a regularização da condiça de posse tradicional das populaçã ribeirinhas da Amazônia.

Está elencada no rol de Direitos Reais que o Código Civil determina em seu artigo 1.125, para atender a fins de interesse social (ABE, 2013). A CDRU é instrumento que pode ser utilizado tanto pelo ente público, quanto pelo particular, e tem seu objeto não só o uso da terra, mas também o espaço aéreo, conforme os termos do contrato. Pode também ser utilizada como instrumento da política urbana, de acordo com o Estatuto da Cidade, Lei n ${ }^{\mathrm{a}}$ 10.257/2001 (DI PIETRO, 2014)

A Lei 11.481/2007 modificou o Decreto-Lei ${ }^{\circ}$ 271/1967, e caracterizou a CDRU como instrumento para regularização fundiária de interesse social, em áreas de várzea e de comunidades tradicionais. Por fim, a Lei $\mathrm{n}^{\circ}$ 11.952/2009 utiliza-a também como instrumento de regularização fundiária das ocupações incidentes em terras situadas em áreas da União no âmbito da Amazônia Legal. Vê-se que é um instrumento políticas públicas.

A Concessão de Direito Real de Uso formaliza-se por instrumento público ou particular, ou mesmo po termo administrativo (ABE, 2013). Deve ter Registro Público em cartório, e possui efeito erga omnes (atinge a coletividade). Também é direito resolúvel, ou seja, pode ser extinta caso a destinação seja diversa a que está em contrato ou termo. Neste caso, perde-se as benfeitorias de qualquer natureza. (DI PIETRO, 2014).

Pode ser remunerada ou gratuita, por tempo certo ou indeterminado, e seu objeto só pode ser terrenos não edificados. $\mathrm{E}$ ainda transferível por ato inter vivos e mortis causa. Por fim, sua concretização só pode se dar por autorização legislativa ou licitação pública (no caso de instrumento público), exceto no casos de "bens imóveis residenciais (...) no âmbito de programas habitacionais ou de regularização fundiaria de interesse social desenvolvidos por or (DI PIETRO,

Também pode ser emitida de forma individual ou coletiva. A Lei no 9.636 de 1998, Art. 18, permite a expedição da CDRU para pessoas físicas e jurídicas, e dispensou o procedimento licitatório no caso de associações e cooperativas que atendam o interesse público ou social. Estendeu, também, a aplicação da CDRU aos terrenos de marinha e acrescidos (ABE, 2013

A sua diferença de outros instrumentos utilizados pela Administração Pública, tais quais a cessão de uso e a concessão de uso, é que nestas, ao se transferir o uso do bem público, a Administração somente gera direitos pessoais ou obrigacionais. Na CDRU, gerase um direito resolúvel, passível de fiscalização pelo agente público e com condições específicas para o uso (ABE, 2013).

Além disto, o artigo 13 da Lei ${ }^{\circ}$ 11.481/07 permitiu que o direito real seja objeto de hipoteca, sendo esta limitada pelo período do contrato de concessão. Isto possibilitou que a CDRU seja garantia real para aceitação pelos agentes financeiros no âmbito do Sistema Financeiro de Habitação, superando assim a dificuldade de utilização de financiamento em áreas de posse ribeirinha.

Assim, como não é possível a titularização de uma posse em terras públicas, o poder público construiu um instrumento a fim de promover o uso sustentável nessas áreas. O Estado continua a ser o titular do domínio, porém transfere a possibilidade de uso, mediante contrato contendo objeto específico, e pode restitui-lo em contrato.

É, de certa forma, a promoção da uma função social dos bens públicos. ACDRU pode proporcionar ao Estado a garantia dos vínculos de ancestralidade com o territorio das populações de várzea e a proteção 
direitos reais derivados da posse antiga dos ribeirinhos nos rios amazônicos. Deve, porém, permitir que os hábitos dessas populações não sejam alterados em virtude do estabelecimento de uma regra fixa para delimitação do território.

\section{CONCLUSÕES}

O histórico de colonização do país se pautou na construção e consolidação do latifúndio disseminação do instituto da posse como forma de acesso à terra da maior parte da população. $\mathrm{Na}$ Amazônia, este processo foi semelhante, porém com a particularidade de que sua colonização foi também em decorrência da explotação de recursos naturais, sem o interesse pelo vínculo com a terra.

Os regimes jurídicos fundiários existentes no Brasil não contemplaram as particularidades das culturas amazônicas. No decorrer do tempo, a população residente nas calhas dos rios amazônicos se estabeleceu em um ambiente de várzea, adotando formas de territorialização específicas. Porém, tais posses antigas não garantem a segurança jurídica para as comunidades tradicionais amazônicas. Esta situação inviabiliza o cumprimento da função socioambiental da posse agrária

Após a promulgação da Constituição Federal de 1988, os movimentos sociais promoveram o início da discussão de garantia jurídica para as famílias extrativistas. Inicialmente, a ideia de Reserva Extrativista e dos Projetos de Assentamento Extrativista foram a tônica da proposta. Mas, com as dificuldades existentes para regularização das áreas protegidas, há que ser discutidas formas individuais e coletivas de regularização fundiária. Atualmente, a Concessão de Direito Real de Uso é um dos instrumentos que possibilita ao Estado e a particulares conceder, a título oneroso ou não, o direito de uso sustentável das áreas de várzea amazônicas.

Ao conceder um direito de uso via CDRU, o Poder Público garante que o domínio de suas terras continue a ser público. $\mathrm{O}$ uso privativo desses bens é condicionado ao interesse público, sendo possível a restituição, caso o ribeirinho não cumpra

com a destinação do bem especificada no contrato. Além disto, por ser possível a concessão individual e coletiva, pode se adequar ao modo de vida e territorialidades destas populações. E um instrumento versátil, inclusive utilizada por diversas políticas públicas de regularização fundiária.

A CDRU permite a segurança jurídica de uma população que historicamente habita as várzeas amazônicas, e que era até então desassistida das políticas públicas e ameaçadas de desterritorialização ocupam. É uma possibilidade para garantir que a Função Social da Posse Agrária atinja seus objetivos elencados pela Carta Constitucional de 1988

\section{REFERÊNCIAS}

ABE, Nilma de Castro. Gestão do patrimônio público imobiliário: aspectos jurídicos da destinação, delimitação, fiscalização e responsabilidade. 2.ed. Belo Horizonte: Fórum, 2013.

ADAMS, Cristina; MURRIETA, Rui; NEVES, Walter. As sociedades caboclas amazônicas: modernidade e invisibilidade (Introdução). In ADAMS, Cristina; MURRIETA, Rui; NEVES Walter (orgs). Sociedades caboclas amazônicas: modernidade e invisibilidade. São Paulo: Annablume, 2006. P. 15-44.

ALLEGRETTI, Mary Helena. Reservas Extrativistas: parâmetros para uma política de desenvolvimento sustentável na Amazônia. In: ANTHONY, Anderson et AL; ARNT, Ricardo (Org.). O destino da floresta: reservas extrativistas e desenvolvimento sustentável na Amazônia. Rio de Janeiro: Relume-Dumará, 1994. 276p.

BECKER, Bertha. Geopolítica da Amazônia Estudos Avançados, v.53, n. 19, 2005. p. 7186. Disponível em <http://www.scielo.br/pdf/ea/ v19n53/24081.pdf $>$. Acesso em $30 \quad$ jan. 2015.

CARVALHO, Vailton Loula de. Formação do
Direito Fundiário Brasileiro. São Paulo: Iglu, 1999. 85 p.

CRUZ, Manuel de Jesus Masulo da. Territorialização camponesa na várzea da Amazônia.2007. 261f. Tese (Doutorado)-Universidade de São Paulo, São Paulo, 2007.

DI PIETRO, Maria Sylvia Zanella. Uso privativo de bem público por particular 3 . ed. São Paulo: Atlas, 2014.

FERES, João Bosco. Propriedade da terra: opressão e miséria: o meio rural na história social do Brasil. Amsterdam: CEDLA Latin America Studies, 1990. 637pgs.

GOMES, Orlando. Direitos Reais. $8^{\mathrm{a}}$ ed. Rio de Janeiro: Forense. 1983.

GUIMARÃES, Alberto Passos. Quatro séculos de latifúndio-1963. In: STEDILE, João Pedro (Org.). A questão agrária no Brasil: o debate tradicional-1500-1960. 2.ed. São Paulo: Expressão popular, 2011. P. 35-77.

MARQUESI, Roberto Wagner. Direitos Reais Agrários e Função Social. 2.ed. Curitiba: Juruá, 2012.202p.

MATTOS NETO, Antônio José de. A questão Agrária no Brasil: aspecto sócio-jurídico. Projeto História, São Paulo, n. 33, p. 97-118, dez. 2006. Disponível em <www.pucsp.br/projetohistoria/ downloads/volume33/artigo_04.pdf $>$. Acesso em 24 jul 2014.

MCGRATH, David G e GAMA, Antônia Socorro Pena da Gama. A situação fundiária da várzea do Rio Amazonas e experimentos de regularização fundiária nos estados do Pará e do Amazonas. In: BENATTI, José Helder. A questão fundiária e o manejo dos recursos naturais da várzea: análise para a elaboração de novos modelos jurídicos. Manaus:
bama/ProVárzea, 2005.

RIBEIRO, Darcy. O Povo Brasileiro: a formação o sentido do Brasil. $2^{\mathrm{a}}$ ed. São Paulo: Companhia das Letras, 2000.

SILVA, Antônio Carlos da Silva; SILVA, Josué da Costa. Seringueiros na Amazônia. COLÓQUIO NACIONAL DO NEER, 2 2006. Disponível em $<$ http://www.neer.com.br/ anais/NEER-2/trabalhos. html>. Acesso em 13 fev. 2015.

TRECCANI, Girolamo Domenico. Regularizar a terra: um desafio para as populações tradicionais de Gurupá, 2006. 725f. Belém: UFPA . Tese ( Doutorado). Belém, UFPA, 2006. 